\title{
Research
}

\section{Delivering brief physical activity interventions in primary care:}

\author{
a systematic review
}

\begin{abstract}
Background

Physical activity (PA) brief interventions

(BIs) involving screening and/or advice are recommended in primary care but frequency of delivery is unknown.
\end{abstract}

\section{Aim}

To examine the extent to which PA Bls are delivered in primary care, and explore factors associated with delivery, receipt, and patient receptivity.

\section{Design and setting}

A mixed-methods systematic review of studies conducted worldwide, with a narrative synthesis of results.

\section{Method}

CINAHL, EMBASE, MEDLINE, and APA PsycINFO index databases were searched for qualitative and quantitative studies, dating from January 2012 to June 2020, that reported the level of delivery and/ or receipt of PA Bls in primary care, and/or factors affecting delivery, receipt, and patient receptivity. Quality was assessed using the Mixed Methods Appraisal Tool. Attitudes towards and barriers to delivery were coded into the Theoretical Domains Framework and the Capability, Opportunity, and Motivation Behaviour model.

\section{Results}

After screening a total of 13066 records,

66 articles were included in the review. The extent of PA screening and advice in primary care varied widely $(2.4 \%-100 \%$ and $0.6 \%-100 \%$, respectively). PA advice was delivered more often to patients with a higher body mass index, lower PA levels, and/or more comorbidities. Barriers - including a lack of time and training/guidelines - remain, despite recommendations from the World Health Organization and National Institute for Health and Care Excellence that PA advice should be provided in primary care. Few studies explored patients' receptivity to advice.

\section{Conclusion}

PA Bls are not delivered frequently or consistently in primary care. Addressing barriers to delivery through system-level changes and training programmes could improve and increase the advice given. Understanding when patients are receptive to PA interventions could enhance health professionals' confidence in their delivery.

\section{Keywords}

brief interventions; disease prevention; health promotion; physical activity; primary care; systematic review.

\section{INTRODUCTION}

Physical inactivity is a global public-health problem. ${ }^{1,2}$ In the UK, levels of inactivity are increasing: approximately 32\% of males and $36 \%$ of females failed to meet the government's physical activity (PA) recommendations in 2018. ${ }^{3}$ Physical inactivity increases the risk of poor physical and mental health, is estimated to account for as many deaths in the UK as smoking lone in six), and costs the NHS around $€ 0.9$ billion annually. ${ }^{4}$

In its Global Recommendations on Physical Activity for Health, the World Health Organization suggests PA advice should be provided in primary care. ${ }^{5}$ Correspondingly, in the UK, the National Institute for Health and Care Excellence (NICE) recommends that primary care practitioners deliver brief PA advice to patients who are not currently meeting PA guidelines. ${ }^{6}$ NICE defines brief advice as verbal advice, discussion, negotiation or encouragement, with or without written or other support or follow-up'.

Previous reviews have found brief interventions (BIs) to be effective at increasing (self-reported) PA in the short term, with some evidence that this can be maintained in the longer term (that is,

LH Hall, PhD, research fellow;

R Rodriguez-Lopez, MPH, information specialist; A Grice, MRCGP, National Institute for Health Research (NIHR) in-practice fellow; RJ Beeken, $\mathrm{PhD}$, associate professor of behavioural medicine, Leeds Institute of Health Sciences, University of Leeds, Leeds. R Thorneloe, PhD, senior research fellow, Centre for Behavioural Science and Applied Psychology, Sheffield Hallam University, Sheffield. MA Thorat, PhD, honorary senior lecturer, Centre for Cancer Prevention, Wolfson Institute of Preventive Medicine, Barts, and The London School of Medicine and Dentistry, Queen Mary University of London, London. K Bradbury, PhD, senior research fellow, NIHR Southampton Biomedical Research Centre, NIHR Applied Research Collaboration Wessex, Southampton. M Wadnerkar Kamble, AFBPsS, lecturer in psychology for speech and language therapy, School of Health Sciences, University of East
12 months). ${ }^{7.8}$ However, barriers to giving and receiving PA advice in primary care are rife; a review in 2012 reported a variety of barriers, including lack of resources and perceived (in)effectiveness of advice. ${ }^{9}$ Since that review was published, the population's PA levels have not substantially increased, ${ }^{10}$ despite various initiatives nationally and globally to increase PA advice delivered in primary care. ${ }^{11,12}$ Additionally, the UK's recent GP workforce crisis $^{13,14}$ may have impacted GPs' capacity to include PA discussions in consultations. Thus, an updated review on barriers and facilitators to delivering PA advice in primary care is warranted. Furthermore, little is known about how often, and to whom, this advice is given. This knowledge is crucial for understanding how PA Bls are implemented in practice and identifying potential areas for improvement. The aim of this mixedmethods systematic review was to:

- examine the extent to which PA Bls (PA screening and/or advice) are delivered in primary care; and

- explore factors associated with delivery, receipt, and patient receptivity.

Anglia, Norwich. GN Okoli, MRCGP, clinical lecturer, Institute of Population Health Sciences, Barts, and The London School of Medicine and Dentistry, Queen Mary University of London, London. D Powell, PhD, lecturer in health psychology, Institute of Applied Health Sciences, University of Aberdeen, Aberdeen.

\section{Address for correspondence}

Rebecca J Beeken, Leeds Institute of Health Sciences, University of Leeds, Leeds LS2 9NL, UK Email: r.beekenaleeds.ac.uk

Submitted: 18 May 2021; Editor's response: 22 June 2021; final acceptance: 2 September 2021.

\section{CThe Authors}

This is the full-length article (published online 16 Nov 2021) of an abridged version published in print. Cite this version as: Br J Gen Pract 2021; DOI: https://doi.org/10.3399/BJGP.2021.0312 


\section{How this fits in}

Physical activity (PA) brief interventions delivered in primary care consultations can increase levels of PA in the general population, but there is a lack of understanding regarding the frequency of, and factors associated with, delivery. This review reports high variation in the frequency and context of delivery and receipt, and outlines common barriers to and facilitators of (coded in the Theoretical Domains Framework and Capability, Opportunity, and Motivation Behaviour modell practitioner delivery. Identified barriers could be addressed through system-level changes, improved educational resources, and training to increase practitioner knowledge and confidence, and subsequently improve patient receptivity and PA uptake.

\section{METHOD}

\section{Search strategy}

Literature index databases were searched for quantitative articles reporting the level of delivery and/or receipt of PA Bls in primary care consultations for health promotion/ disease prevention, and quantitative/ qualitative articles reporting factors affecting delivery, receipt, and patient receptivity. In July 2018, and again in July 2020, an information specialist carried out separate searches of the Cumulative Index to Nursing and Allied Health Literature (CINAHL), EMBASE, MEDLINE, and American Psychological Association (APA) PsycINFO databases; Supplementary Box S1 provides example search terms for PsycINFO. The review was prospectively registered on PROSPERO, an international prospective register of systematic reviews (reference: CRD42018103812).

\section{Article selection and data extraction}

Two authors screened the titles and abstracts using the specified inclusion criteria loutlined in Supplementary Box S2) and erring on the side of inclusion. Three authors then reviewed $20 \%$ of the titles and abstracts to ensure reliability. In all, $20 \%$ of the full-texts were double-screened by two authors, and disagreements were arbitrated by a third author. References of included articles were hand searched for additional eligible studies.

In total, $100 \%$ of the data were extracted in duplicate by four independent authors using an electronic spreadsheet. Discrepancies were checked by another reviewer. Key study characteristics are given in Supplementary Table S1, and the main outcomes of patient and practitioner receipt/delivery of PA BIs (levels of screening and advice) are outlined in Supplementary Tables S3 and S4.

\section{Quality assessment}

Study quality was assessed by one reviewer using the Mixed Methods Appraisal Tool; ${ }^{15}$ $20 \%$ of studies were assessed by a second reviewer and checked for consistency.

\section{Analysis}

In order to examine the extent to which PA Bls are delivered in primary care, quantitative data were extracted on the reported frequency of:

- PA screening;

- delivery of PA advice by health professionals; and

- patient-reported receipt of PA BIs.

A quantitative synthesis of these data was not possible, because of large heterogeneity in the definition and measurement of PA Bls. A narrative synthesis was, therefore, conducted.

In order to explore factors associated with delivery, receipt, and patient receptivity, quantitative data were extracted inductively from articles, in duplicate, by four reviewers; these were then coded as either patient or health professional/system factors. Qualitative data on health professionals attitudes and perceived barriers towards delivery, as well as patients' views, attitudes, and receptivity towards PA Bls, were extracted inductively from the articles using the articles' own phrasing/codes. Similar codes were grouped together by one reviewer who has expertise in behaviour change theory. Codes relating to health professionals' attitudes or barriers were mapped onto the Theoretical Domains Framework (TDF) and Capability, Opportunity, and Motivation Behaviour (COM-B) model by that same reviewer and one other to assist in the identification of key components for future interventions aiming to increase PA BI delivery.

\section{RESULTS}

The database searches identified 13066 records, once duplicates were removed (Figure 1), and 59 eligible articles. ${ }^{16-74}$ Hand-searching references identified seven further studies, ${ }^{75-81}$ giving a total of 66 articles that could be included in the review. The majority of studies $(n=40)$ included data collected from health professionals, ${ }^{17-22,25,26,28-}$ $30,33,34,36,37,39,42-46,49,50,56-59,65,66,69-72,75-81$ and used cross-sectional surveys $(n=54))^{16-}$ 19,21,22,27-34,36-61,63-68,71,73,74,77-81 Many studies 


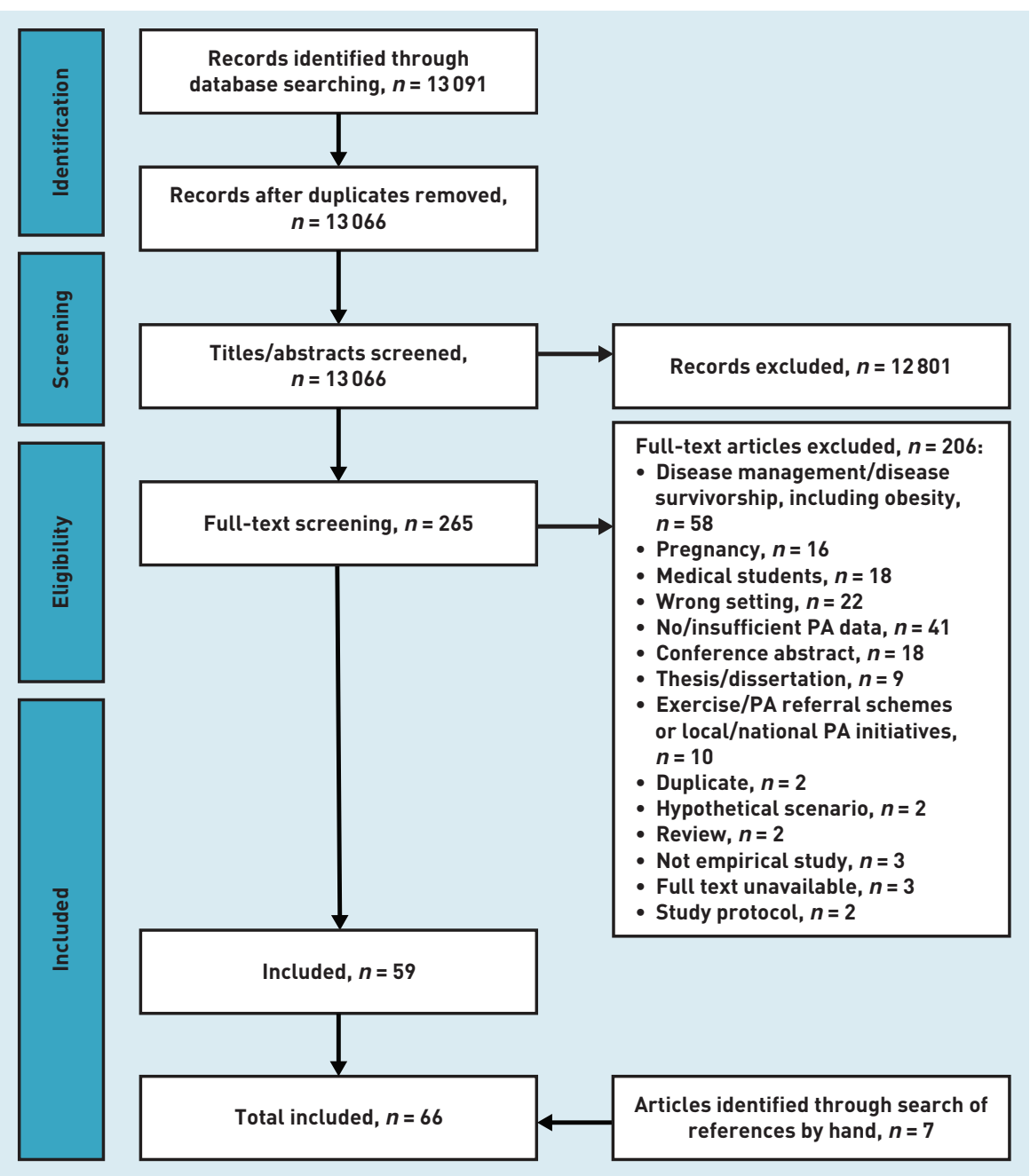

Figure 1. Flow diagram of article search and inclusion process.

$P A=$ physical activity .
( $n=32)$ were conducted (in whole or part) in North American populations (Supplementary Table S1). 16,22,24-27,31,33,35,38,39,42$46,48,50,52,53,56,57,62,63,66,68,71-74,77,78$

\section{Quality assessment}

The majority of studies were of moderate quality. Most quantitative descriptive studies used appropriate statistical analyses (94\%) and appropriate measurements (81\%), many of which were pilot tested, and/or developed using Delphi methods or in consultation with key stakeholders. The risk of nonresponse bias and the representativeness of the target population was either unclear or inadequate in around half of these studies (Supplementary Table S2).

\section{Level of PA screening by health professionals}

Eleven studies reported the level of PA screening by practitioners (Figure 2; Supplementary Table S3). $22,28,30,36,37,42,43,50,56,58$, 78 Data from medical chart audits in one medium-quality study reported that the proportion of patients who had their PA levels assessed ranged, depending on appointment type, from $2.4 \%$ (unplanned visits) to $60.1 \%$ (annualvisits) (median 43.5\%). ${ }^{22}$ The proportion of practitioners who reported assessing PA for at least some of their patients ranged from $8 \%{ }^{28}$ to $100 \%$ (median $50 \%$ ). ${ }^{78}$

\section{Level of brief PA advice by health professionals}

Thirty-one studies (reported in 32 articles) presented the extent to which practitioners provided PA advice or counselling (Figure 2; Supplementary Table S3). ${ }^{17-19,21,22,24,26,28-}$ $30,34,36,37,39,43-46,49,56-58,65,66,70,71,75,76,78-81 \quad$ The proportion of practitioners who reported delivering PA advice/counselling ranged from $0.6 \%^{21}$ to $100 \%$ (median $64.0 \%$ ). ${ }^{78,80}$ One high-quality study analysed audiotaped consultations and reported (in two articles) that PA was discussed in $72 \%$ of patient visits. ${ }^{24,26}$ In contrast, the proportion of patients who were given PA advice/ counselling, as determined by medical chart audit (in one medium-quality study), ranged, depending on appointment type, from $1.5 \%$ (unplanned visits) to $52.2 \%$ (annual visits) (median 23.3\%). ${ }^{22}$

\section{Patient-reported receipt of PA BI}

Twenty-five studies (reported in 26 articles) provided data on patient receipt of $\mathrm{PA} \mathrm{BI}$ (Figure 2; Supplementary Table S4). 16,24,27,31$33,38,40,41,43,44,47,48,51-55,60,61,63,64,67,68,74,76 \quad$ The proportion of patients reporting that they had received PA advice ranged from $7.7 \%$ (of females, $9.4 \%$ of males) to $76 \%$ (median $35 \%,{ }_{4}^{40,63}$ with 13 studies reporting that $<40 \%$ of patients recalled receiving PA advi ce. ${ }^{16,31,38,40,41,47,48,51,53,54,60,64,67}$ Reviewing audiotaped discussions highlighted that 21\% of patients could not accurately recall PA discussions that occurred. ${ }^{24}$

\section{Factors associated with the delivery or receipt of PA BI}

Patient factors. Twenty-three studies (reported in 24 articles) examined patient factors associated with $\mathrm{PA} B \mathrm{BI}$ (Supplementary Table S5). 16,17,22,27,36,38,40,41,44,45,47. $52-54,60,61,63,64,67,68,73,74,80,81$ Although the majority of evidence was mixed and inconclusive, the following patient factors were most consistently reported to be significantly and positively associated with the delivery or receipt of $\mathrm{PABI}$ :

- high patient body mass index $(n=12) ; 16,38,40,45,47,53,54,60,63,67,68,73$

- physically inactive/sedentary patients $(n=6) ; 38,47,53,54,60,67$ 


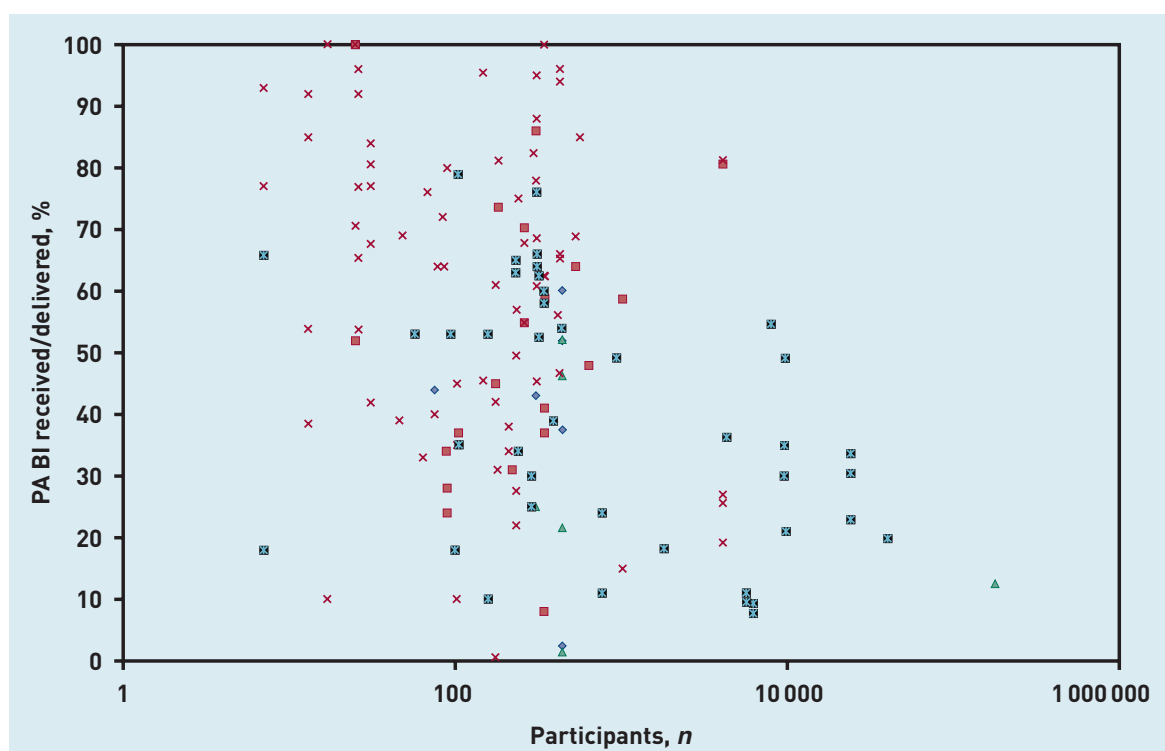

- Screening by medical chart review

$\times$ Advice reported by health professional

- Screening reported by health professional a Patient reported advice/screening

$\triangle$ Advice by medical chart review
Figure 2. Percentage of patients receiving physical activity brief interventions in primary care. $B I=$ brief intervention. $P A=$ physical activity .
- poorer health/greater number of comorbidities ( $n=5) ; 38,53,60,67,73$ and

- greater number of physician visits ( $n=4)^{16,44,45,53}$

Patient sex $22,38,40,60,61,64,68,73$ and age $^{22,36,38,40,60,61}$ were often found not to be associated with PA BI

\section{Health}

professional/system

factors. Twenty-four studies examined practitioner/system factors associated with PA BI (Supplementary Table S6). ${ }^{17-19,22,28-}$ $30,34,36,37,42,45,47-49,55,57,60,61,67,71,77,79,81$ The majority of findings were inconsistent, except the following two points:

- female practitioners were more likely than male practitioners to assess PA (but not necessarily advise); 17,22,30,42,49 and

- practitioners with higher levels of PA themselves, 19,29,42,79 and practitioners with positive beliefs about their capabilities and/or efficacy, ${ }^{22,30,37,42}$ were more likely to deliver PA BI.

\section{Health professionals' attitudes and perceived barriers towards PA BI}

Twenty-six quantitative 17-19,22,28,30,33,34,36,37,39 $42,43,46,49,50,56-59,65,69,71,78,80,81$ and two qualitative studies $^{20,70}$ examined health professionals' attitudes towards delivering PA BI. These were coded into the $\mathrm{TDF}^{82}$ and $\mathrm{COM}-\mathrm{B}^{83}$ model (Supplementary Table S7).
Capabilities (psychological). Twenty

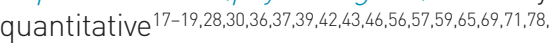
80,81 and one qualitative study ${ }^{70}$ reported barriers and facilitators that were coded under psychological capabilities; of these, 19 studies reported attitudes that fit into the TDF domain of 'knowledge'. 17-19,28,30,36,37,39,46,56,57,59,65,69-71,78,80,81 In 12 of these, $17,19,37,39,56,57,59,69,70,78,80,81$ health professionals reported a personal lack of knowledge or training as a barrier to providing $\mathrm{PAB}$, with a request for additional training also mentioned. 46 However, the majority of health professionals in six studies perceived they had sufficient knowledge or skills. ${ }^{18,30,36,39,46,65}$ In two out of four studies that were coded under the TDF domain of 'skills', practitioners reported having difficulty advising patients or including advice in their appointments. ${ }^{30,57}$

Opportunity (physical). Fifteen

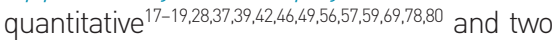
qualitative studies 20,70 measured attitudes that were coded under the TDF domain of 'environmental context and resources', and the COM-B model category of "physical opportunity'. The most commonly cited barriers within these themes were:

- perceived time constraints for including PA discussions in consultations ( $n=17) i^{17-20,28,37,39,42,46,49,56,57,59,69,70,78,80}$ and

- a perceived lack of local services or places to which patients could be referred I $n=8)^{17,20,28,37,49,56,69,80}$

Further barriers included:

- perceived (lack of) availability of educational resources for health professionals; ${ }^{19,39,56}$

- (lack of) effective tools/information to give to patients; ${ }^{17,19,20,56,78}$ and

- perceived (lack of) opportunities to follow up on PA advice. $20,57,70$

Motivation (reflective and automatic). The most commonly coded TDF category within 'motivation' was 'beliefs about consequences' ( $n=19)$. 17, 18,20,28,36,37,39,42,46,49,56$59,65,69,71,78,80$ Within this domain, the most commonly reported barriers to delivery of PA BI were health professionals' perceived:

- (lack of) patient interest, motivation, or likelihood of adhering to advice ( $n=14) ; 17,18,20,28,39,42,46,49,56-59,78,80$

- patient expectation of receiving pharmacological $(n=6) ; 17,18,39,56,57,78$ and 
- (lack of) effectiveness of PA advice ( $n=7)^{17,39,56-58,71,78}$

Despite these barriers, most practitioners thought that PA Bls were a part of their role $(n=11)^{17,18,20,28,30,42,43,49,59,69,80}$ and important $(n=7) ; 36,37,42,65,69,71,78$ the majority felt confident about their capabilities Iselfefficacy) in providing PA Bls and supporting behaviour change $\ln =822,28,30,33,50,58,59,65$ of 13 studies measuring confidence/selfefficacy ${ }^{20,22,28,30,33,34,36,39,50,57-59,65}$ ).

\section{Patients' views, attitudes, and receptivity towards PA BIs}

Four high-quality qualitative studies ${ }^{25,35,62,72}$ explored patient views and attitudes towards PA advice in primary care. Patients felt they had no regular conversations about PA, and that PA conversations lacked substance. The need for a patient-centred approach with follow-up communication was mentioned and some patients were receptive to PA advice if it was clearly linked to contextual factors, such as the potential to reduce medication or pain. Some patients, however, believed practitioners lacked the confidence and knowledge to deliver PA BI, which influenced their receptivity towards advice. In spite of this, provider motivation and support were viewed as important for behaviour change.

\section{DISCUSSION}

\section{Summary}

This mixed-methods review of 66 studies conducted worldwide suggests high variation in the extent to which PA is discussed with patients in primary care. Key practitioner barriers included a lack of time and training/guidelines, and a perceived lack of patient motivation/adherence to PA advice. Few studies have explored patients' receptivity to such advice; however, conversations with clear relevance to the patient's contextual factors (for example, medication) appear to be valued.

\section{Strengths and limitations}

To the authors' knowledge, this review is the first to report on the prevalence of $\mathrm{PA} B \mathrm{~B}$ in primary care, and to link health professionals perceived barriers and facilitators to the COM-B model and TDF. However, only articles written in English were included because of a lack of translation resources, and only $20 \%$ of article screening and quality assessment was conducted in duplicate. As only peer-reviewed, published articles were included, a publication bias may have been present.

This review focuses solely on PA screening and advice; studies that examined specific exercise-referral schemes or prescriptions (including social prescribing) were excluded. Future research may benefit from comparing the frequencies of these. Because of a lack of detail in the articles, it was not possible to code Behaviour Change Techniques, despite a plan to do so in the review protocol. In addition, the large degree of heterogeneity of outcome measures made cross-study and crosscultural comparisons challenging.

The quality of studies was often reduced by the sample not being representative of the target population (or there being a lack of detail to assess this), and a high risk of non-response bias; as such, caution should be taken when generalising findings. It is possible - especially in the sample of health professionals - that those with a particular interest in PA were more likely to participate; as a result, the prevalence of PA BI reported in this review may be an overestimation.

\section{Comparison with existing literature}

This review provides an update of the literature on provider and patient barriers to delivering/receiving PA advice, following Campbell et al's (2012) review.9 It extends their work through coding provider attitudes and barriers into the TDF and COM-B model. Similar provider barriers were identified - namely, perceived likelihood of patient uptake, lack of resources (for example, time and materials), and health professionals confidence and knowledge. Lamming et al's (2017) umbrella review also reported time as a key practitioner barrier. ${ }^{7}$ It is notable that these barriers remain, despite an increased awareness of the importance of PA and recommendations from the World Health Organization and NICE on the delivery of PA interventions. 5,6 There is a clear need to identify meaningful ways to tackle these persistent challenges.

Comparing PA with other behaviourchange discussions indicates that those relating to diet, weight, and smoking are often discussed more frequently, whereas those relating to alcohol are discussed less often. $31,32,41,47,48,58,65,71$ Furthermore, a survey undertaken in Sweden and the US reported that more patients wanted to receive support on diet, weight, and smoking than on PA. ${ }^{48}$ Therefore, PA discussions could be conducted alongside advice on diet and/or weight to increase delivery frequency and patient receptivity.

\section{Implications for research and practice}

PA Bls were more frequently delivered to patients with a higher body mass index, 


\section{Funding}

This review was supported by Yorkshire Cancer Research (reference: L389RB) and Cancer Research UK (reference: A23517). Mangesh A Thorat is supported by a Cancer Research UK programme grant Ireference: C569/A168911. Daniel Powell is supported by the strategic research programme funded by the Scottish Government's Rural and Environment Science and Analytical Services (RESAS) Division. Rebecca J Beeken is supported by Yorkshire Cancer Research Fellowship funding (reference: L389RB).

\section{Ethical approval}

Not required.

\section{Provenance}

Freely submitted; externally peer reviewed.

\section{Competing interests}

The authors have declared no competing interests.

\section{Contributors}

Louise H Hall and Rachael Thorneloe are joint first authors.

\section{Open access}

This article is Open Access: CC BY 4.0 licence (http://creativecommons.org/ licences/by/4.0/).

\section{Discuss this article}

Contribute and read comments about this article: bjgp.org.uk/letters a greater number of comorbidities, and to those who were physically inactive. Practitioners must, therefore, be cautious not to stigmatise patients when deciding when, and how, to conduct these conversations because, if the patient feels they are being stigmatised, it could have a detrimental effect on their psychological and physical health, ${ }^{84}$ and increase inactivity. ${ }^{85}$

Patients often under-reported receiving PA advice, suggesting that training for health professionals that focuses on delivery skills may be needed to increase patient engagement with advice. Opportunistic PA Bls tailored to what is realistically feasible around each patient's lifestyle are likely to be most effective.

The parallels between health professionals' perceived barriers to Bls for PA compared with those for smoking cessation $^{86}$ and obesity ${ }^{87}$ - notably, time constraints, lack of experience, and lack of patient motivation - suggest a cultural shift is desirable to address health professionals giving preventive behaviour change interventions lower priority, compared with disease management lincluding pharmacotherapy)..$^{88}$ Although any attempts to address the physical inactivity epidemic are multifaceted, with a need to engage all stakeholders, primary care professionals have a key role owing to the high frequency of patient contact ${ }^{89}$ and the trust patients put in health professionals. ${ }^{90}$

To address this challenge, health professionals - and GPs in particular need evidence to realise that behavioural interventions have an important place in holistic patient-centred, evidence-based medicine, and reassurance that patients will engage with, and benefit from, them. Health professionals also need clear interventions to offer, with education at undergraduate and postgraduate level, and mandatory within continuing professional development. The recently launched UK's Moving Medicine toolkit (https://movingmedicine. ac.uk) may help overcome knowledge and resource barriers. However, a recent study demonstrated that, despite educational training successfully addressing GPs' barriers to providing opportunistic weightloss interventions during a trial, after the trial ended, GPs reported the same barriers as pre-trial; ${ }^{91}$ therefore, wider system changes may also be required.

There is limited qualitative research on patient views on receiving PA interventions in primary care, and three of the four studies in this review were limited to samples of adults aged $>60$ years living in North America. ${ }^{25,35,72}$ Research is needed on patient receptivity towards PA discussions in the UK, and among people of a wider age range, to inform practitioner training and increase patient engagement with advice.

Only four studies were UK based, 34,41,51,55 and all indicated that rates of PA BI are low: $15 \%$ of GPs reported delivering PA advice to all patients, $18 \%-35 \%$ of patients reported receiving advice, and $53 \%$ of patients reported PA screening. More research is needed in the UK to better understand the prevalence of factors associated with, and barriers to and enablers for, delivering and receiving $\mathrm{PA} \mathrm{BI}$ in UK primary care.

As current research fails to adequately describe the content of PA interventions, it is not possible to comment on the quality of advice given. Future research would benefit from describing the $\mathrm{Bl}$ and the context in which it is delivered, using the Behaviour Change Taxonomy ${ }^{92}$ and the Template for Intervention Description and Replication (TIDieR) Checklist. ${ }^{93}$

Prevalence of the delivery and receipt of PA Bls in primary care varies widely, with many studies reporting low levels of delivery/receipt. Health professionals have identified a number of barriers to delivering PA advice, including time, knowledge, and confidence. Addressing these barriers through system-level changes and training programmes could improve the consistency, quality, and frequency of advice given. A better understanding of when patients are most receptive to PA interventions in primary care could enhance the interventions' effectiveness and increase health professionals' confidence to discuss PA with their patients. 


\section{REFERENCES}

1. Lee I-M, Shiroma EJ, Lobelo F, et al. Effect of physical inactivity on major noncommunicable diseases worldwide: an analysis of burden of disease and life expectancy. Lancet 2012; 380(9838): 219-229.

2. World Health Organization. Global action plan on physical activity 2018-2030: more active people for a healthier world. 2018. https://apps.who.int/iris/bitstream/ handle/10665/272722/9789241514187-eng.pdf (accessed 8 Nov 2021).

3. NHS Digital. Statistics on obesity, physical activity, and diet, England, 2019. 2019 https://digital.nhs.uk/data-and-information/publications/statistical/statistics-onobesity-physical-activity-and-diet/statistics-on-obesity-physical-activity-and-dietengland-2019 (accessed 8 Nov 2021)

4. Public Health England. Physical activity: applying All Our Health. 2019. https:// www.gov.uk/government/publications/physical-activity-applying-all-our-health laccessed 8 Nov 2021).

5. World Health Organization. Global recommendations on physical activity for health. 2010. https://www.who.int/publications/i/item/9789241599979 laccessed 8 Nov 2021).

6. National Institute for Health and Care Excellence. Physical activity: brief advice for adults in primary care. PH44. London: NICE, 2013. https://www.nice.org.uk/ guidance/ph44 (accessed 8 Nov 2021).

7. Lamming L, Pears S, Mason D, et al. What do we know about brief interventions for physical activity that could be delivered in primary care consultations? A systematic review of reviews. Prev Med 2017; 99: 152-163.

8. Orrow G, Kinmonth A-L, Sanderson S, Sutton S, et al. Effectiveness of physical activity promotion based in primary care: systematic review and meta-analysis of randomised controlled trials. BMJ 2012; 344: e1389.

9. Campbell F, Blank L, Messina J, et al. Physical activity: brief advice for adults in primary care. 2012. https://uww.nice.org.uk/quidance/ph44/evidence/review-ofeffectiveness-and-barriers-and-facilitators-69102685 (accessed 8 Nov 2021).

10. Du Y, Liu B, Sun Y, et al. Trends in adherence to the physical activity guidelines for Americans for aerobic activity and time spent on sedentary behavior among US adults, 2007 to 2016. JAMA Netw Open 2019; 2(7): e197597.

11. Royal College of General Practitioners. Clinical priorities. https://uww.rcgp.org.uk/ clinical-and-research/our-programmes/clinical-priorities.aspx laccessed 8 Nov 2021).

12. Health Education and Improvement Wales. Motivate 2 Move. 2013. https://gpcpd heiw.wales/clinical/motivate-2-move laccessed 8 Nov 2021).

13. Hall LH, Johnson J, Watt I, O'Connor DB, et al. Association of GP wellbeing and burnout with patient safety in UK primary care: a cross-sectional survey. $\mathrm{Br} J \mathrm{Gen}$ Pract 2019; DOI: https://doi.org/10.3399/bjgp19X702713.

14. Owen K, Hopkins T, Shortland T, Dale J. GP retention in the UK: a worsening crisis. Findings from a cross-sectional survey. BMJ Open 2019; 9(2): e026048.

15. Hong QN, Fàbregues S, Bartlett G, et al. The Mixed Methods Appraisal Tool (MMAT) version 2018 for information professionals and researchers. Education for Information 2018; 34(4): 285-291.

16. Ahmed NU, Delgado M, Saxena A. Trends and disparities in the prevalence of physicians' counseling on exercise among the US adult population, 2000-2010. Prev Med 2017; 99: 1-6.

17. Alahmed Z, Lobelo F. Correlates of physical activity counseling provided by physicians: a cross-sectional study in Eastern Province, Saudi Arabia. PloS One 2019; 14(7): e0220396.

18. Al-Ghamdi S, Alajmi M, Al-Gonaim A, et al. Perceptions and attitudes of primary healthcare providers in Riyadh City, Saudi Arabia, towards the promotion of physical activity. International Journal of Health Promotion and Education 2017; DOI: 10.1080/14635240.2018.1430601

19. Aljaberi A. Assessment of physical activity (counseling) at primary health care centers in Aseer Region, Saudi Arabia. Medical Journal of Cairo University 2014: 82(2): 207-213.

20. Allender S, Hayward J, Gupta S, et al. Bayesian strategy selection identifies optimal solutions to complex problems using an example from GP prescribing. NPJ Digit Med 2020; 3: 7.

21. Ameh PO, Yakubu K, Miima M, et al. Lifestyle, cardiovascular risk knowledge and patient counselling among selected sub-Saharan African family physicians and trainees. Afr J Prim Health Care Fam Med 2019; 11(1): e1-e15.

22. Baillot A, Baillargeon J-P, Paré A, et al. Physical activity assessment and counseling in Quebec family medicine groups. Can Fam Physician 2018; 64(5): e234-e241.
23. Banday AH, Want FA, Alris FFA, et al. A cross-sectional study on the prevalence of physical activity among primary health care physicians in Aljouf region of Saudi Arabia. Mater Sociomed 2015; 27(4): 263-266.

24. Bardach SH, Schoenberg NE, Howell BM. Older patients' recall of lifestyle discussions in primary care. J Appl Gerontol 2017; 36(4): 386-400.

25. Bardach SH, Schoenberg NE. The role of primary care providers in encouraging older patients to change their lifestyle behaviors. Clin Gerontol 2018; 41(4): 326-334.

26. Bardach SH, Schoenberg NE. The content of diet and physical activity consultations with older adults in primary care. Patient Educ Couns 2014; 95(3): 319-324.

27. Barnes PM, Schoenborn CA. Trends in adults receiving a recommendation for exercise or other physical activity from a physician or other health professional. NCHS Data Brief2012; (86): 1-8.

28. Barrett EM, Darker CD, Hussey J. Promotion of physical activity in primary care: knowledge and practice of general practitioners and physiotherapists. Journal of Public Health 2013; 21: 63-69.

29. Belfrage ASV, Grotmol KS, Tyssen R, et al. Factors influencing doctors' counselling on patients' lifestyle habits: a cohort study. BJGP Open 2018; DOI: https://doi.org/10.3399/bjgpopen18X101607.

30. Bock C, Diehm C, Schneider S. Physical activity promotion in primary health care: results from a German physician survey. Eur J Gen Pract 2012; 18(2): 86-91.

31. Brauer PM, Sergeant LA, Davidson B, et al. Patient reports of lifestyle advice in primary care. Can J Diet Pract Res 2012; 73(3): 122-127.

32. Brotons C, Bulc M, Sammut MR, et al. Attitudes toward preventive services and lifestyle: the views of primary care patients in Europe. The EUROPREVIEW patient study. Fam Pract 2012; 29 Suppl 1: i168-i176.

33. Carroll JK, Winters PC, Sanders MR, et al. Clinician-targeted intervention and patient-reported counseling on physical activity. Prev Chronic Dis 2014; 11: E89.

34. Chatterjee R, Chapman T, Brannan MG, Varney J. GPs' knowledge, use, and confidence in national physical activity and health guidelines and tools: a questionnaire-based survey of general practice in England. Br J Gen Pract 2017 DOI: https://doi.org/10.3399/bjgp17X692513.

35. Costello E, Leone JL, Ellzy M, Miller TA. Older adult perceptions of the physicians' role in promoting physical activity. Disabil Rehabil 2013; 35(14): 1191-1198.

36. Diehl K, Mayer M, Mayer F, et al. Physical activity counseling by primary care physicians: attitudes, knowledge, implementation, and perceived success. J Phys Act Health 2015; 12(2): 216-223.

37. Florindo $\mathrm{AA}$, Mielke $\mathrm{Gl}$, Gomes $\mathrm{GAO}$, et al. Physical activity counseling in primary health care in Brazil: a national study on prevalence and associated factors. BMC Public Health 2013; 13: 794.

38. Forjuoh SN, Lee C, Won J, et al. Correlates of receiving a recommendation for more physical activity from a primary care provider. Am J Prev Med 2017; 52(2): 207-214

39. Fowles JR, O'Brien MW, Solmundson K, et al. Exercise is Medicine Canada physical activity counselling and exercise prescription training improves counselling, prescription, and referral practices among physicians across Canada. Appl Physiol Nutr Metab 2018; 43(5): 535-539.

40. Gabrys L, Jordan S, Schlaud M. Prevalence and temporal trends of physical activity counselling in primary health care in Germany from 1997-1999 to 20082011. Int J Behav Nutr Phys Act 2015; 12: 136.

41. Gaglani J, Oakeshott P. Conducting a survey of patient reported advice on diet and exercise in primary care. Educ Prim Care 2018; 29(3): 178-179.

42. Galaviz KI, Jauregui-Ulloa E, Fabrigar LR, et al. Physical activity prescription among Mexican physicians: a structural equation analysis of the theory of planned behaviour. Int J Clin Pract 2015; 69(3): 375-383.

43. Galaviz Kl, Estabrooks PA, Jauregui-Ulloa E, et al. Evaluating the effectiveness of physician counseling to promote physical activity in Mexico: an effectivenessimplementation hybrid study. Transl Behav Med 2017; 7(4): 731-740.

44. Gauri A, Rodriguez X, Gaona P, et al. Communication between low income Hispanic patients and their healthcare providers regarding physical activity and healthy eating. J Community Health 2017; 42(6): 1220-1224.

45. Goldberg DM, Cho B-Y, Lin H-C. Factors influencing US physicians' decision to provide behavioral counseling. Prev Med 2019; 119: 70-76.

46. Grimstvedt ME, Ananian CD, Keller $\mathrm{C}$, et al. Nurse practitioner and physician assistant physical activity counseling knowledge, confidence and practices. Prev Med 2012; 54(5): 306-308

47. Harris MF, Islam FM, Jalaludin B, et al. Preventive care in general practice among healthy older New South Wales residents. BMC Fam Pract 2013; 14: 83 
48. Jerdén L, Dalton J, Johansson $\mathrm{H}$, et al. Lifestyle counseling in primary care in the United States and Sweden: a comparison of patients' expectations and experiences. Glob Health Action 2018; 11(1): 1438238.

49. Jørgensen TK, Nordentoft M, Krogh J. How do general practitioners in Denmark promote physical activity? Scand J Prim Health Care 2012; 30(3): 141-146.

50. Katz A, Lambert-Lanning A, Miller A, et al. Delivery of preventive care: the national Canadian family physician cancer and chronic disease prevention survey. Can Fam Physician 2012; 58(1): e62-e69.

51. Lall K, Oakeshott P. Educating primary care patients with and without hypertension about lifestyle changes: a medical student audit at an inner-city practice. Educ Prim Care 2019; 30(2): 124-125.

52. Leavitt PT, Morozov H, Wright D. Patient preferences of primary care support to increase physical activity. Journal for Nurse Practitioners 2019; 15(7): e135-e138.

53. Loprinzi PD, Beets MW. Need for increased promotion of physical activity by health care professionals. Prev Med 2014. 69: 75-79.

54. Lundin A, Hallgren M, Danielsson A-K. Screening in primary care for alcohol use compared with smoking, diet, and physical activity: a repeated population survey in Sweden. J Stud Alcohol Drugs 2019; 80(1): 109-113.

55. Morton S, Thompson D, Wheeler $\mathrm{P}$, et al. What do patients really know? An evaluation of patients' physical activity guideline knowledge within general practice. London J Prim Care (Abingdon) 2016; 8(4): 48-55.

56. O'Brien M, Shields C, Crowell S, et al. The effects of previous educational training on physical activity counselling and exercise prescription practices among physicians across Nova Scotia: a cross-sectional study. Can Med Educ J 2018; 9(4): e35-e45.

57. O'Brien MW, Shields CA, Oh PI, Fowles JR. Health care provider confidence and exercise prescription practices of Exercise is Medicine Canada workshop attendees. Appl Physiol Nutr Metab 2017; 42(4): 384-390.

58. Obeidat NA, Habashneh MA, Shihab RA, Hawari FI. Are Jordanian primary healthcare practitioners fulfilling their potential in cancer prevention and community health? Findings from a cross-sectional survey. BMJ Open 2017; 7(4): e015269.

59. Oyeyemi AL, Oyeyemi AY, Habib RY, et al. A survey of physicians and physiotherapists on physical activity promotion in Nigeria. Arch Physiother 2017; 7: 5

60. Pechter Ü, Suija K, Kordemets T, et al. Physical activity and exercise counselling a cross-sectional study of family practice patients in Estonia. Qual Prim Care 2012; 20(5): 355-363.

61. Petek D, Platinovsek R, Klemenc-Ketis Z, Kersnik J. Do family physicians advise younger people on cardiovascular disease prevention? A cross-sectional study from Slovenia. BMC Fam Pract 2013; 14: 82.

62. Reddeman $\mathrm{L}$, Bourgeois N, Angl EN, et al. How should family physicians provide physical activity advice? Qualitative study to inform the design of an e-health intervention. Can Fam Physician 2019; 65(9): e411-e419.

63. Reilly M, Ayala GX, Elder JP, Patrick K. Physician communication and physical activity among Latinas. J Phys Act Health 2013; 10(4): 602-606.

64. Rodríguez MM, Castillo JMD, Sánchez JAS, et al. Associations among physician advice, physical activity, and socio-demographic groups in older Spanish adults. Can J Aging 2012; 31(3): 349-356.

65. Schneider S, Diehl K, Bock C, et al. Modifying health behavior to prevent cardiovascular diseases: a nationwide survey among German primary care physicians. Int J Environ Res Public Health 2014; 11(4): 4218-4232.

66. Sherman MD, Hooker SA. Family medicine physicians' confidence and perceived effectiveness in delivering health behaviour change interventions. Fam Pract 2020; 37(4): 493-498.

67. Short CE, Hayman M, Rebar AL, et al. Physical activity recommendations from general practitioners in Australia. Results from a national survey. Aust N Z J Public Health 2016; 40(1): 83-90.

68. Shuval K, DiPietro L, Skinner CS, et al. 'Sedentary behaviour counselling': the next step in lifestyle counselling in primary care; pilot findings from the Rapid Assessment Disuse Index (RADI) study. Br J Sports Med 2014. 48(19): 1451-1455.

69. Smit E, Leenaars KEF, Wagemakers A, et al. Perceptions of care sport connectors' tasks for strengthening the connection between primary care, sports and physical activity: a Delphi study. Int J Integr Care 2020; 20(1): 13.

70. Wattanapisit A, Thanamee S, Wongsiri S. Physical activity counselling among GPs: a qualitative study from Thailand. BMC Fam Pract 2019; 20(1): 72

71. Weinehall $L$, Johansson $H$, Sorensen J, et al. Counseling on lifestyle habits in the United States and Sweden: a report comparing primary care health professionals' perspectives on lifestyle counseling in terms of scope, importance and competence. BMC Fam Pract 2014; 15: 83.

72. Weiss DR, Wolfson C, Yaffe MJ, et al. Physician counseling of older adults about physical activity: the importance of context. Am J Health Promot 2012; 27(2): 71-74.

73. Yang H-Y, Chen H-J, Hsu Y-J, et al. Impact of weight-related advice from healthcare professionals on body mass index of patients in the USA. Public Health 2018; 159: 50-57.

74. Yang H-Y, Chen $\mathrm{H}-\mathrm{J}$, Marsteller JA, et al. Patient-health care professional gender or race/ethnicity concordance and its association with weight-related advice in the United States. Patient Educ Couns 2016; 99(2): 271-278.

75. Geense WW, van de Glind IM, Visscher TLS, van Achterberg T. Barriers, facilitators and attitudes influencing health promotion activities in general practice: an explorative pilot study. BMC Fam Pract 2013; 14: 20.

76. Aittasalo M, Kukkonen-Harjula K, Toropainen E, et al. Developing physical activity counselling in primary care through participatory action approach. BMC Fam Pract 2016; 17(1): 141.

77. Pronk NP, Krebs-Smith SM, Galuska DA, et al. Knowledge of energy balance guidelines and associated clinical care practices: the US National Survey of Energy Balance Related Care among Primary Care Physicians. Prev Med 2012; 55(1): 28-33.

78. Windt J, Windt A, Davis J, et al. Can a 3-hour educational workshop and the provision of practical tools encourage family physicians to prescribe physical activity as medicine? A pre-post study. BMJ Open 2015; 5(7): e007920.

79. Voltmer E, Frank E, Spahn C. Personal health practices and patient counseling of German physicians in private practice. International Scholarly Research Notices 2013; DOI: 10.5402/2013/176020

80. Leemrijse CJ, de Bakker DH, Ooms L, Veenhof C. Collaboration of general practitioners and exercise providers in promotion of physical activity a written survey among general practitioners. BMC Fam Pract 2015; 16: 96.

81. Joyce $\mathrm{CL}, \mathrm{O}$ 'Tuathaigh $\mathrm{CM}$. Increased training of general practitioners in Ireland may increase the frequency of exercise counselling in patients with chronic illness: a cross-sectional study. Eur J Gen Pract 2014; 20(4): 314-319.

82. Cane J, O'Connor D, Michie S. Validation of the theoretical domains framework for use in behaviour change and implementation research. Implement Sci2012; 7: 37 .

83. Michie S, Atkins L, West R. The behaviour change wheel: a guide to designing interventions. London: Silverback Publishing, 2014: 1003-1010.

84. Puhl RM, Heuer CA. Obesity stigma: important considerations for public health. Am J Public Health 2010; 100(6): 1019-1028.

85. Jackson SE, Steptoe A. Association between perceived weight discrimination and physical activity: a population-based study among English middle-aged and older adults. BMJ Open 2017; 7(3): e014592.

86. Vogt F, Hall S, Marteau TM. General practitioners' and family physicians' negative beliefs and attitudes towards discussing smoking cessation with patients: a systematic review. Addiction 2005; 100(10): 1423-1431.

87. Warr W, Aveyard P, Albury C, et al. A systematic review and thematic synthesis of qualitative studies exploring GPs' and nurses' perspectives on discussing weight with patients with overweight and obesity in primary care. Obes Rev 2021; 22(4): e13151.

88. Ribera AP, McKenna J, Riddoch C. Attitudes and practices of physicians and nurses regarding physical activity promotion in the Catalan primary health-care system. Eur J Public Health 2005; 15(6): 569-575

89. Brooks J, Ahmad I, Easton G. Promoting physical activity: the general practice agenda. Br J Gen Pract 2016; DOI: https://doi.org/10.3399/bjgp16X686689.

90. Schofield G, Croteau K, McLean G. Trust levels of physical activity information sources: a population study. Health Promot J Austr 2005; 16(3): 221-224.

91. Kebbe M, Jebb SA, Begh R, et al. General practitioner views on addressing weight opportunistically in primary care: an embedded sequential mixed-methods study. Patient Educ Couns 2021; DOI: 10.1016/j.pec.2021.06.028.

92. Michie S, Richardson M, Johnston M, et al. The behavior change technique taxonomy (v1) of 93 hierarchically clustered techniques: building an international consensus for the reporting of behavior change interventions. Ann Behav Med 2013; 46(1): 81-95.

93. Hoffmann TC, Glasziou PP, Boutron I, et al. Better reporting of interventions: template for intervention description and replication (TIDieR) checklist and guide. $B M J 2014 ;$ 348: g1687. 